Faculdade

de Ciências Econômicas UFRGS

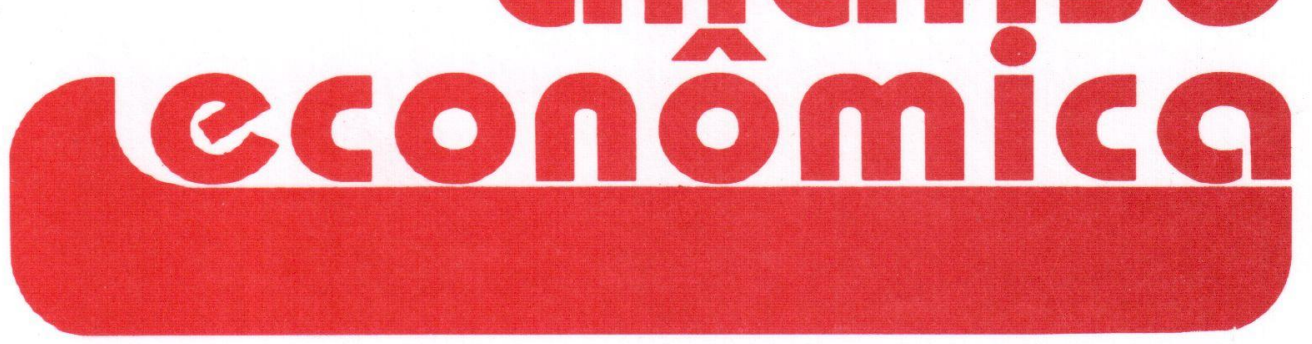

Balança Comercial e Capacidade

Produtiva da Indústria de Transformação

- Flávio Benevett Fligenspan

- Jeferson Luis Bittencourt

Breves Reflexões sobre a Relevância

da História da Teoria Econômica

- Gilberto Tadeu Lima

A Competitividade do Arroz Gaúcho

e seus Condicionantes

- Augusto M. Alvim

- Carlos G. A. Mielitz Netto

Uma Análise da Economia de Ricardo

- Liderau S. Marques Junior

A Estratégia de Substituição de

Importações Revisitada

- Alex Pereira Benício

- Joanílio Rodolpho Teixeira

The Refinements of the Orthodox Macroeconomic Theory and the Post Keynesian Theory

- Fernando Ferrari Filho

Instrumentos de Gestão Ambiental

- Jaildo Santos Pereira

- Vitor Emanuel Tavares

The Economic Implications for

Sustainable Mining

- Dina Franceschi

- James R. Kahn

Mudança Institucional e Estrutural na

Economia Brasileira do Início dos Anos Noventa

- Eduardo Simões de Almeida
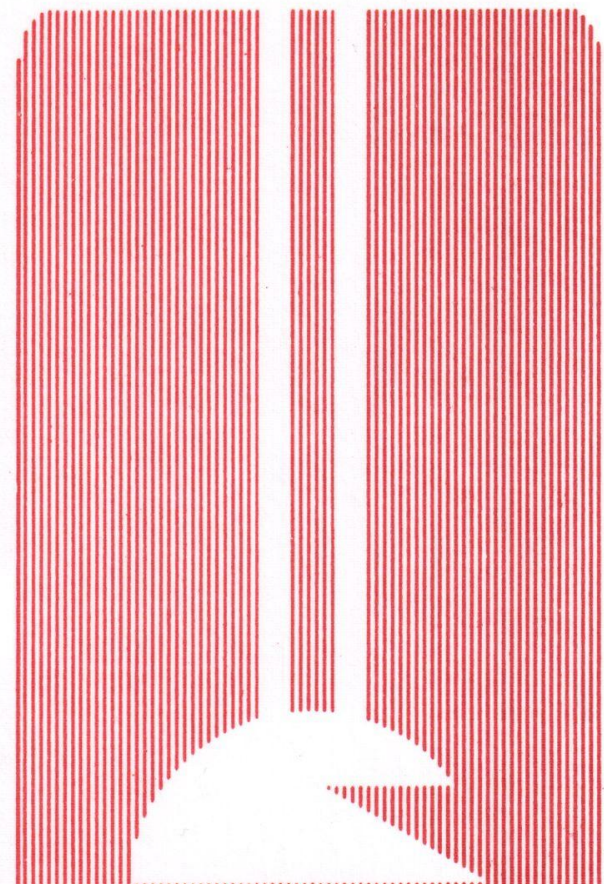

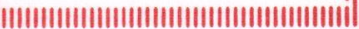
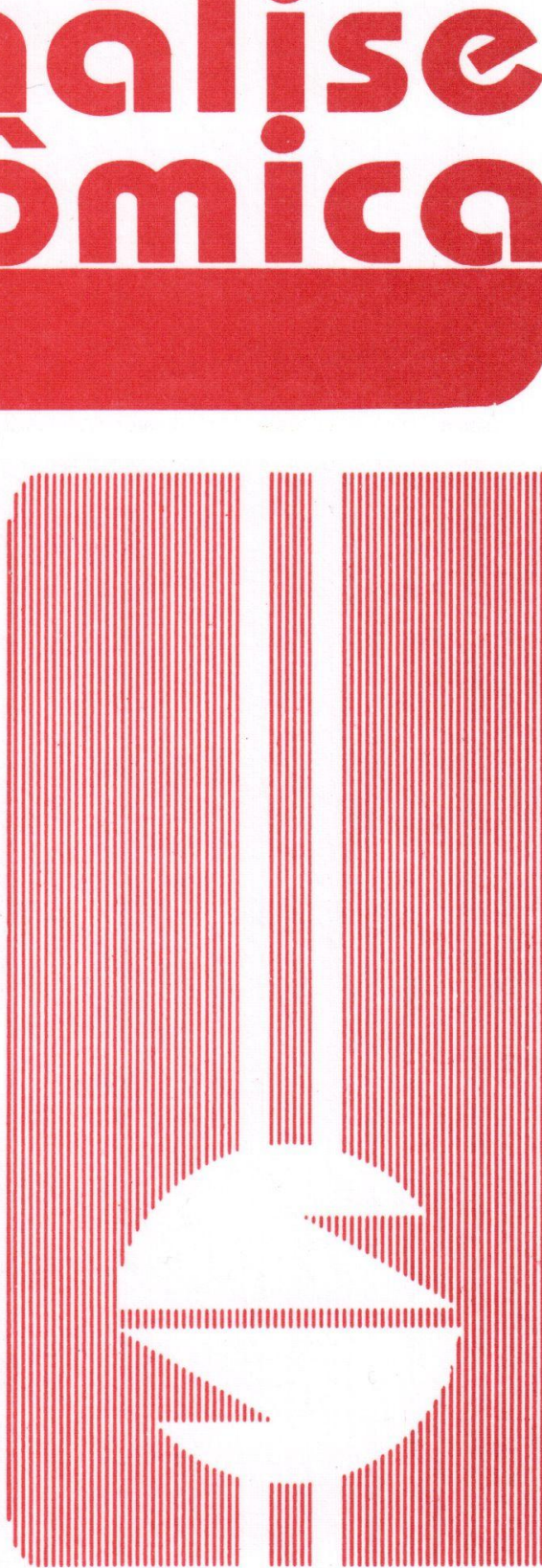
UNIVERSIDADE FEDERAL DO RIO GRANDE DO SUL

Reitora: Prof ${ }^{a}$. Wrana Maria Panizzi

FACULDADE DE CIÊNCIAS ECONÔMICAS

Diretora: Prof . Otilia Beatriz Kroeff Carrion

CENTRO DE ESTUDOS E PESQUISAS ECONÔMICAS

Diretor. Prof. Fernando Ferrari Filho

DEPARTAMENTO DE CIÊNCIAS ECONÔMICAS

Chefe: Prof. Luiz Alberto Oliveira Ribeiro de Miranda

CURSO DE PÓS-GRADUAÇÃO EM ECONOMIA

Coordenador. Prof. Marcelo Savino Portugal

CURSO DE PÓS-GRADUAÇÃO EM ECONOMIA RURAL

Coordenador. Prof. Carlos Guilherme A. Mielitz Netto

CONSELHO EDITORIAL: Achyles B. Costa, Aray M. Feldens, Carlos A. Crusius, Carlos G. A. Mielitz Netto, Eduardo A. Maldonado Filho, Eduardo P. Ribeiro, Eugênio Lagemann, Fernando Ferrari Filho, Gentil Corazza, Marcelo S. Portugal, Nali J. Souza, Otília B. K. Carrion, Paulo A. Spohr, Paulo D. Waquil, Pedro C. D. Fonseca, Roberto C. Moraes, Ronald Otto Hillbrecht, Stefano Florissi, Eleutério F. S. Prado (USP), Fernando H. Barbosa (FGV/RJ), Gustavo Franco (PUC/RJ), João R. Sanson (UFSC), Joaquim P. Andrade (UnB), Juan H. Moldau (USP), Paul Davidson (Univ. of Tennessee), Werner Baer (Univ. of lllinois).

COMISSÃO EDITORIAL: Eduardo Augusto Maldonado Filho, Fernando Ferrari Filho, Gentil Corazza, Marcelo Savino Portugal, Paulo Dabdab Waquil; Roberto Camps Moraes.

EDITOR: Gentil Corazza

EDITOR ADJUNTO: Pedro Silveira Bandeira

SECRETARIA: Fábio Sparremberger. Revisão de textos: Vanete Ricacheski.

FUNDADOR: Prof. Antônio Carlos Santos Rosa

Os materiais publicados na revista Análise Econômica são da exclusiva responsabilidade dos autores. É permitida a reprodução total ou parcial dos trabalhos, desde que seja citada a fonte. Aceita-se permuta com revistas congêneres. Aceitam-se, também, livros para divulgação, elaboração de resenhas e recensões. Toda correspondência, material para publicação (vide normas na terceira capa), assinaturas e permutas devem ser dirigidos ao seguinte destinatário:

PROF. GENTIL CORAZZA

Revista Análise Econômica - Av. João Pessoa, 52 CEP 90040-000 PORTO ALEGRE - RS, BRASIL 


\title{
A COMPETITIVIDADE DO ARROZ GAÚCHO E SEUS CONDICIONANTES
}

\author{
Augusto M. Alvim ${ }^{1}$ \\ Carlos Guilherme A. Mielitz Netto ${ }^{2}$
}

\begin{abstract}
SINOPSE
O presente estudo identifica os principais fatores que afetaram a produção de arroz no Estado do Rio Grande do Sul e a sua competitividade no mercado brasileiro. O setor arrozeiro brasileiro apresentou significativas mudanças na sua cadeia agroalimentar após o fim da política de incentivos e créditos subsidiados, a abertura comercial e a formação do Mercosul, que determinaram modificações substanciais na distribuição da produção no Brasil, na qualidade do produto e na estrutura produtiva do setor.
\end{abstract}

Cód. AEA: 711

Palavras-chave: arroz, oferta e competitividade.

\section{ABSTRACT}

This study aims to identify the main factors affecting rice supply in the state of Rio Grande do Sul and its competitiveness in Brazilian market. The Brazilian rice sector showed significant changes in the food chain after new agricultural policies, market liberalization and the Mercosul creation, which determined significant modifications in the allocation of production, in the quality of rice and in the productive structure of this sector.

AEA Cod: 711

Key Words: rice, supply and competitiveness.

\footnotetext{
${ }^{1}$ Eng. Agr. e Mestre em Economia Rural/UFRGS. E-mail: mussi@vortex.ufrgrs.br.

2 Doutor em Economia, professor adjunto do Departamento de Ciências Econômicas e do Curso de pós-graduação em Economia Rural (CPGER) da Universidade Federal do Rio Grande do Sul (UFRGS). Av. João Pessoa, n³ 31, CEP 90040-060, Porto Alegre, RS. Email: mielitz@vortex.ufrgs.br.
}

N. 31

Março/99

p. $45-58$ 


\section{1 - APRESENTAÇÃO}

A agricultura brasileira, nos últimos 20 anos, foi submetida a políticas econômicas que modificaram de forma significativa o volume total produzido, a distribuição da produção, a estrutura produtiva e a competitividade dos diversos setores da agropecuária.

O modelo de expansão da produção agrícola, implementado durante a década de sessenta baseado em um programa nacional de incentivos e créditos subsidiados às novas tecnologias, em barreiras comerciais aos produtos internacionais e incentivos a exportação de produtos agrícolas, esgotou-se no início da década de 80.

Com isto, na década de 80 , ocorreu uma mudança na intensidade e na qualidade da intervenção do Estado brasileiro deixando a produção agrícola mais submetida às influências do mercado. Contudo, somente com a abertura da economia brasileira intensificada a partir de 1990 e com a tendência brasileira em diminuir as barreiras alfandegárias ao comércio internacional é que a agricultura brasileira ficou mais subordinada às influências do mercado mundial.

Particularmente no caso do arroz, principalmente a partir da década de 90 , o Brasil tornou-se um importador devido às mudanças nas politicas brasileiras que determinaram profundas modificações na produção e nos preços resultantes deste novo equilíbrio.

A partir deste cenário, a competitividade do arroz gaúcho sofreu alterações significativas durante o período de 1975 a 1995. Conseqüentemente, buscou-se neste trabalho analisar os fatores que afetaram a competitividade do arroz no Rio Grande do Sul (RS). Entende-se por competitividade, a capacidade de um conjunto de firmas de conquistarem uma determinada participação no mercado (market share), num certo momento do tempo.

Para compreender o aumento da participação do arroz gaúcho no mercado nacional, foram analisadas as principais mudanças políticas, econômicas e na eficiência produtiva que determinaram o aumento de sua competitividade no mercado brasileiro.

\section{2- POLÍTICAS AGRÍCOLAS}

A partir da safra de 1984/85, a política de incentivos e créditos subsidiados acabou de forma definitiva. O total de crédito agropecuário foi reduzido a $1 / 3$ do concedido no final dos anos setenta, sendo o crédito para investimentos o mais atingido pelos cortes. Os principais instrumentos utilizados a 
partir desta nova fase para financiar a agricultura foram o $A G F^{3}$ e o EGF em duas modalidades COV e SOV $^{5}$ (Silva, 1992).

Além da redução dos incentivos governamentais às atividades agricolas, no período de 1985 a 1991, ocorreram vários planos de estabilização econômica incapazes de controlar a inflação e o déficit público, mas que submeteram o mercado agrícola a um conjunto de medidas que resultaram em maiores variações nos preços agrícolas, aumentando, com isto, o risco na atividade agrícola, o que contribuiu para o surgimento de uma parcela de agricultores endividados.

Gráfico 1 - Crédito para custeio e relação entre o crédito concedido para o RS e o crédito concedido no Brasil para a lavoura arrozeira - 1985 a 1995

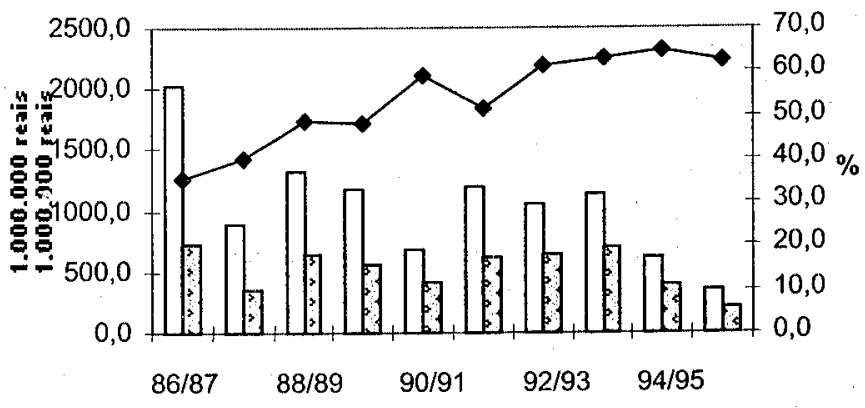

Fonte: Banco Central, 1985-95.

Atualizado pelo IGP-Di médio anual.

$\square$ Brasil $\square$ RS $\rightarrow$ RS/Brasil

Devido ao endividamento dos agricultores, principalmente dos produtores de arroz, algumas medidas de alívio ao setor foram tomadas até meados de 1997. A securitização conseguiu renegociar aproximadamente 580,0 milhões de reais, o que representa $40,0 \%$ dos débitos dos orizicultores do RS. Em algumas áreas do Centro-Oeste cerca de $80,0 \%$ dos produtores de

\footnotetext{
${ }^{3}$ Aquisição do Governo Federal - é o preço mínimo que o governo garante ao produtor logo após a colheita, em que o beneficiário vende a sua produção por intermédio do Banco do Brasil.

${ }^{4}$ Empréstimo do Governo Federal com opção de venda - por intermédio desse instrumento o Governo Federal pode quitar a divida do beneficiário com o banco, pagando todo o saldo do financiamento, que inclui despesas tais como taxa de classificação, armazenagem, encargos financeiros (até o limite oficialmente estabelecido para o crédito rural), sobretaxa e seguro.

${ }^{5}$ Empréstimo do Governo Federal sem opção de venda - neste o beneficiário tem a obrigação de liquidar o financiamento recebido para comercialização até o vencimento.
} 
arroz não tiveram seus créditos repactuados; comprometendo uma parte significativa da produção nacional (As Dívidas, 1997).

Esta situação explica, em parte, porque o crédito rural concedido para os agricultores de arroz sofreu uma maior redução nas safras de 1994/95 e 1995/96 (vide Gráfico 1). O endividamento junto ao setor bancário impossibilitou que uma parte dos agricultores tomasse o crédito para custeio ou para a comercialização.

Segundo o Gráfico 1, o crédito total concedido para custeio da lavoura de arroz no Brasil vem reduzindo ano após ano, entretanto esta diminuição do crédito nos outros Estados brasileiros vem sendo maior do que no Estado do RS, principalmente após o ano de 1990. No periodo de 1985 a 1996, o crédito concedido para a lavoura arrozeira no Brasil reduziu $71,9 \%$, enquanto no RS no mesmo período reduziu $63,3 \%$.

Esta tendência do Governo em conceder uma maior parcela de crédito ao RS, incrementou-se a partir da década de 80 . Em 1975, os arrozeiros gaúchos recebiam ao redor de $25,0 \%$ do crédito total concedido as lavouras de arroz, enquanto, em 1985, esta participação aumentou para $43,0 \%$, chegando em 1995 a quase $63,0 \%$ do total de crédito nacional concedido para as lavouras de arroz no RS. Isto ocorreu simultaneamente com a redução na área plantada de arroz na maior parte dos demais Estados brasileiros e com a expansão da produção neste Estado (Banco Central, 1975-1995).

Em termos gerais esta menor redução do crédito para custeio ao RS em relação às demais Regiões brasileiras favoreceu aos produtores deste Estado. Contudo é importante considerar que o volume de crédito concedido nos últimos anos, reduziu também para o RS, prejudicando a produção neste Estado, já que uma parcela significativa destes agricultores está descapitalizada e depende do crédito concedido junto a instituições financeiras para iniciar o plantio.

\section{3- POLÍTICAS BRASILEIRAS COM RELAÇÃO AO COMÉRCIO EXTERIOR}

Devido ao modelo de substituição das importações, adotado pelo governo brasileiro, o fechamento da economia tornou-se um fator causador de crescente defasagem tecnológica da agricultura e da indústria brasileira e de incentivo à manutenção de empresas ineficientes. As mudanças nas políticas de comércio exterior começaram a partir de 1990 através de duas vias. A primeira delas ocorreu com a redução das barreiras tarifárias e nãotarifárias a produtos importados.

A outra forma de abertura comercial aconteceu com formação do Mercosul. Um dos marcos mais relevantes que contribuiu para a formação deste mercado foi a assinatura da "Ata de Buenos Aires" que deu início a um processo de liberalização comercial entre o Brasil e a Argentina. Entre- 
tanto apenas em 26 de março de 1991 com o Tratado de Assunção, é que se formou o Mercosul, inicialmente entre a Argentina, o Brasil, o Paraguai e o Uruguai.

O Mercosul tinha como objetivo principal o fim das tarifas e de outras restrições não-tarifárias, entre os paises membros até o final de 1994. Entretanto haveria uma redução tarifária gradativa até este período onde seria estabelecido o livre comércio, marcado para 1995.

Concomitantemente a esta isenção tarifária entre países do Mercosul, foi também estabelecida uma Tarifa Externa Comum (TEC), com o objetivo de proteger uniformemente os paises do bloco frente aos preço baixos do mercado internacional.

Em função destas modificações nas politicas de comércio exterior, a política tarifária do arroz pode ser dividida em três fases. A primeira até o ano de 1990, em que as tarifas externas se situavam ao redor de $20,0 \%$, com intervenções do governo rebaixando tarifas ou liberando as importações, conforme a sua necessidade pelo produto no mercado interno.

Num segundo periodo, de 1991 a 1994, caracterizado pela entrada do Brasil no Mercosul, em que as importações de arroz de países do bloco recebiam descontos sobre a tarifa brasileira básica do arroz, quando começa a haver uma vantagem maior em importar este produto destes paises. Outro aspecto importante nesta fase é que a tarifa para paises fora do Mercosul, ainda era definida pelo governo brasileiro, ocasionando ainda variações significativas nas tarifas aduaneiras.

Na última fase foram zeradas as tarifas entre os países do Mercosul e definidas as TECs para cada produto. Esta fase teve alguns efeitos positivos sobre a produção de arroz como, por exemplo, tornou a tarifa mínima externa fixa, sendo necessário um acordo mútuo entre os países que compõem o bloco para alterá-la, o que dificulta bastante o processo de uma redução tarifária para terceiros países e permite uma maior estabilidade de preços aos produtores.

Além dos aspectos tarifários, a forma de pagamento e a taxa de juros para importação de qualquer produto determinam a facilidade ou urna forma disfarçada de determinar barreiras contra outros países. A partir de 1990, o longo prazo de pagamento das importações (que ia de 8 a 12 meses), aliado aos juros internacionais menores (entre $6,0 \%$ e $8,0 \%$ a.a.), contribuiram para um aumento no volume de importações de arroz (Perspectivas, 1996).

Mais recentemente, devido ao excesso de importações, à redução da renda agrícola e ao aumento da perda de divisas, o governo tomou algumas medidas para reduzir o déficit na balança comercial. Em 28 de fevereiro de 1995, foram criadas medidas que submetem o arroz importado de terceiros países, com destino a região Centro-Sul, ao pagamento à vista pelo produto 
(importações para os Estados do Nordeste foram excluídas desta medida) (USDA, 1995).

Com isto, o arroz importado de paises como Estados Unidos e Vietnã teria que ser pago à vista, enquanto importações originárias do Mercosul, além de possuir a tarifa de importação igual a zero, poderiam ser compradas com um prazo de 180 dias (prazo mais freqüente) e sem Taxas Marítimas da Marinha Mercantil de 25,0\%, aplicadas sobre o valor do frete, como os terceiros países são submetidos (USDA, 1995).

Como a maior parte das importações é feita por grandes empresas brasileiras $^{6}$, com financiamentos diretos nas empresas argentinas e uruguaias, conseguindo através deste processo reduzir custos (custos como, por exemplo, da abertura de carta de crédito), isto levou a um aumento das importações de arroz com origem em paises do Mercosul, a partir de 1995.

Este conjunto de alterações nas politicas de comércio exterior, como mudanças tarifárias e de normas para financiamento para importação, alterou os volumes e as origens das importações de arroz feitas pelo Brasil, neste período.

As importações de arroz pelo Brasil são originárias dos países do Mercosul (especificamente da Argentina e do Uruguai), aumentando ainda mais a participação destes países após 1995, com a criação da União Aduaneira.

Segundo a CNA (1997), cerca de $87,0 \%$ das importações brasileiras provêm do Mercosul, sendo $56,0 \%$ do Uruguai e $31,0 \%$ da Argentina. De países fora do Mercosul se destacam o arroz originário do Vietnã e dos Estados Unidos, os quais foram prejudicados após 1995 devido à obrigatoriedade do pagamento à vista. Contudo, nos anos de 1991 e 1994, ainda foram expressivas as importações de arroz de terceiros paises como do Estados Unidos, Tailândia e Vietnã.

O período de 1991 a 1997, em que se observam os maiores volumes de arroz importado (vide Gráfico 2), coincide também com o período em que a moeda brasileira esteve mais valorizada em relação ao dólar americano. Esta valorização da moeda brasileira determinou um aumento nos custos de produção no Brasil, devido aos maiores preços da terra de cultivo, sementes, mão-de-obra, serviços, entre outros, em relação aos demais países. Conforme pode ser observado no Anexo 1, conjuntamente, estes fatores correspondem a mais de $80,0 \%$ dos custos de produção de arroz.

\footnotetext{
${ }^{6}$ A maior parte das internalizações no Brasil são feitas através de três a quatro tradings que fazem a internalização do produto da origem para os empacotadores ou diretamente para as grandes redes varejistas. Estas firmas localizam-se em sua grande maioria no Estado do RS, explicando a razão pela qual mais de $40,0 \%$ das importações brasileiras destinam-se a região Sul, mesmo não sendo aqui o destino para o consumo deste produto (Perspectivas, 1996; FNP, 1996).
} 


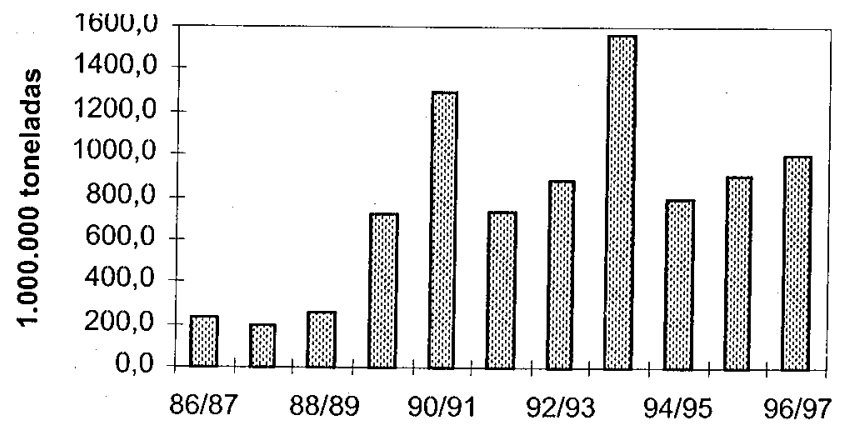

Fonte: CONAB, 1997

R importações - base casca

Este aumento dos custos brasileiros em função da valorização da moeda, juntamente com as demais políticas de abertura comercial, contribuíram para que ocorresse um incremento na quantidade de arroz importado de outros países.

Entretanto as políticas de comércio exterior também afetaram a indústria a montante, a qual produz fertilizantes, agrotóxicos, máquinas e implementos. Esta, após 1990, ficou mais submetida à concorrência internacional, causando uma redução nos preços domésticos, devido aos menores preços no mercado exterior, o que amenizou o impacto negativo da abertura comercial e da valorização cambial sobre a produção nacional. Na Tabela abaixo apresenta-se a intensidade da redução tarifária para os diversos insumos agrícolas.

Tabela 1 - Tarifas de importação de insumos e equipamentos para a agricultura (\%) - 1990 a 1993

\begin{tabular}{l|r|r|r|r}
\hline \multicolumn{1}{c|}{ Produto } & jul./90 & ago./90 & out./90 & \multicolumn{1}{c}{ jul./93 } \\
\hline Adubos e fertilizantes & $5-25,0$ & $0-10,0$ & $0-10,0$ & $0-10,0$ \\
Matérias-primas químicas & $30-40,0$ & 20,0 & 20,0 & 20,0 \\
Inseticidas e fungicidas & 40,0 & 20,0 & 20,0 & 20,0 \\
Equipamentos agricolas & 40,0 & 25,0 & 20,0 & 20,0 \\
Tratores & 65,0 & 40,0 & 30,0 & 20,0 \\
\hline
\end{tabular}

Fonte: Tab, apud Kume, 1995. p.182.

Conforme pode ser observado na Tabela 1, as alíquotas foram diminuídas em cerca de $50,0 \%$, exceto para os tratores, cuja queda foi de aproximadamente um terço e, posteriormente, tiveram uma redução de dez pontos na percentagem em cada etapa. 
Em termos gerais, na política de comércio exterior brasileira, observouse uma tendência à liberalização de mercado aliada a uma valorização cambial, com o objetivo básico de reduzir os preços internos dos produtos brasileiros. Estas políticas determinaram mudanças na produção de arroz e reflexos em toda cadeia agroalimentar de arroz brasileiro, como será discutido na próxima seção.

\section{4- MERCADO BRASILEIRO DE ARROZ}

Com a regionalização dos preços mínimos, redução dos créditos para custeio, diminuição da garantia de compra pelo governo e redução das barreiras ao comércio internacional, a cultura de arroz no Brasil começou a entrar em decadência, e culturas como a da soja e algodão começaram a avançar sobre as áreas de arroz, resultando em redução da produção de arroz, principalmente na região Centro-Oeste.

A partir destes acontecimentos, ocorreu uma mudança no perfil da produção brasileira de arroz, a partir de 1986. Na safra de $1985 / 86,61,0 \%$ da produção eram de arroz longo (sequeiro), enquanto somente $39,0 \%$ eram de arroz longo fino (irrigado). Na safra de 1992/93 a produção de arroz sequeiro correspondia a $42,5 \%$ e a de arroz irrigado a $55,5 \%$, sendo que em 1995 a produção de arroz irrigado estava ao redor de 60,0\% (As Tendências, 1992).

Entretanto esta mudança não foi devida somente a uma redução na produção das demais Regiões brasileiras, mas também pelo aumento da produção no RS. Sendo este responsável por $80,0 \%$ do arroz irrigado brasileiro, a expansão na produção neste Estado determinou também uma mudança no perfil da produção brasileira de arroz.

O desenvolvimento de cultivares, os novos métodos de produção e as novas formas de organização constituem-se nos principais fatores do desenvolvimento da orizicultura no RS. Variedades desenvolvidas pelo IRGA nos últimos anos têm registrado produtividades que aicançam os $10.000,0$ $\mathrm{kg} / \mathrm{ha}$, ou seja, o dobro do rendimento médio que vem ocorrendo no Estado desde o início da década de 80 (Plano, 1997).

Os novos métodos de produção como, por exemplo, o plantio direto e o pré-germinado, que aumentaram o rendimento por hectare em áreas com maior incidência de arroz vermelho, vêm gradativamente substituịndo os sistemas de plantio convencionais. ${ }^{7} \mathrm{E}$ as novas formas de organização empresarial que permitiram uma melhor utilização dos recursos disponiveis através da informática e do maior acesso as informações de mercado. Como resultado destas inovações tecnológicas, a tendência da produção de

${ }^{7}$ ver Alvim (1998) 
arroz no período de 1975 a 1995 mostrou-se crescente, conforme apresenta-se no Gráfico 3.

\section{Gráfico'3 - Produção de arroz no RS - 1975 a 1995}

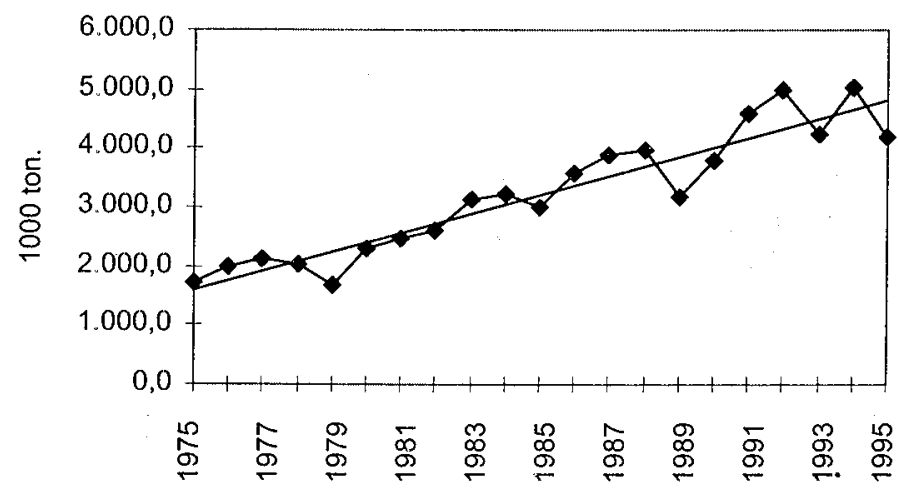

Fonte: IBGE, 1975 a 1995

A aumento da tecnologia permitiu, de um lado, o aumento da produtividade, conforme comentado acima e, de outro, lado fez com que os custos médios de produção também reduzissem. $O$ aumento da produtividade e a redução de custos proporcionaram ao produtor de arroz um aumento na receita líquida, estimulando a produção de arroz.

Os custos médios de produção de arroz nas duas últimas décadas reduziram também pelos menores preços pagos dos insumos empregados na produção, apesar da carga tributária elevada na cadeia do arroz e do alto custo de arrendamento (ao redor de $25,0 \%$ do valor produzido). Os preços pagos pelos insumos empregados na produção contribuíram significativamente na redução dos custos, já que estes correspondem a mais de $15,0 \%$ dos custos totais (Anexo 1).

Porém a redução nos preços dos insumos, isoladamente, não determinou o aumento da rentabilidade nesta atividade, já que a redução nos preços pagos foi a uma taxa inferior a dos preços recebidos neste mesmo período. Esta relação desfavorável entre preço recebido e preço pago, no período de 1987 a 1995 apresenta-se no Gráfico 4. 
Gráfico 4 - Relação entre a variação no preço recebido versus variação no preço pago - 1970 a 1995

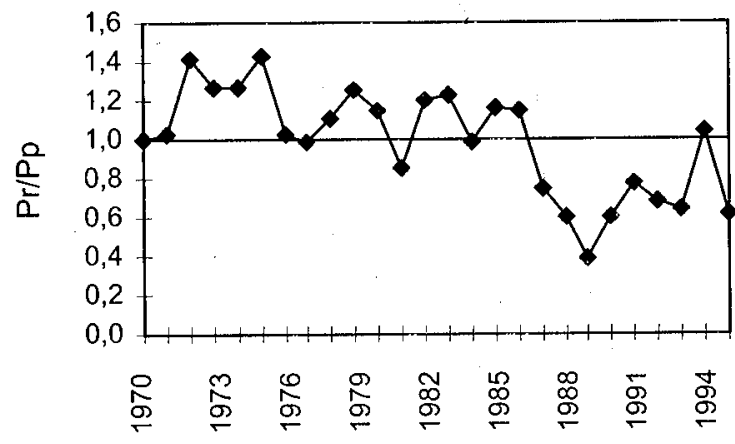

Fonte: Conjuntura, 1970 a 1995.

Esta distorção, resultante de uma maior variação nos preços pagos em relação aos preços recebidos, criou uma desvantagem em relação aos produtores dos paises dos quais o Brasil importa arroz. Esta é resultante, principalmente, do aumento da concentração industrial das empresas ligadas à produção de arroz que, devido ao poder de mercado obtido, ofertam insumos agrícolas relativamente mais caros que os preços dos produtos agrícolas demandados pela agroindústria.

Mesmo com uma maior pressão para a redução dos preços recebidos pelos agricultores, a produção de arroz incrementou neste período. Este incremento na produção no RS, dada a utilização de novas tecnologias, explica também o aumento da participação do arroz gaúcho no mercado brasileiro, visualizado no Gráfico 5 .

$\mathrm{O}$ aumento na participação da produção do arroz gaúcho em relação ao total consumido, bem como uma queda acentuada na participação dos outros Estados ficam demonstrados quando comparamos os três períodos abaixo definidos. Em 1975, a participação do arroz gaúcho no mercado brasileiro era de $21,7 \%$, enquanto no periodo de 1985 a 1990 , a participação média subiu para $34,9 \%$, chegando a uma média de $41,6 \%$ no período de 1991 a 1995 (vide Gráfico 5). 
Conseqüentemente, somente com o aumento da tecnologia e a utilização de áreas mais apropriadas para o plantio de arroz, foi possível obter um ganho líquido na redução dos custos médios na produção de arroz e aumentar a receita por hectare, obtida através de uma maior produtividade por área. Em outras palavras, o efeito tecnologia foi fator determinante do aumento na rentabilidade desta atividade, contrapondo-se a todos fatores de

\section{Gráfico 5- Participação do arroz gaúcho}

no mercado brasileiro - 1975 a 1995

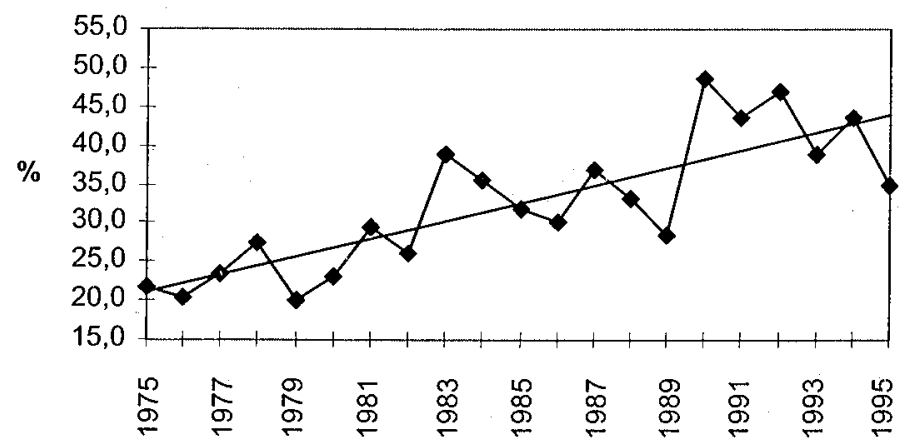

Fonte: IBGE, 1975 a 1995

FAO, 1975 a 1995

$\longrightarrow$ Participação no mercado brasileiro
$\longrightarrow$ Tendencia

ordem política e econômica que atuaram no sentido de reduzir a produção e a competitividade.

\section{5- CONSIDERAÇÕES FINAIS}

Conforme discutido anteriormente, ocorreram diversos fatores negativos ao aumento na produção de arroz no Brasil, como a redução de crédito para investimentos e para custeio, a redução dos preços mínimos, o endividamento dos agricultores, a abertura comercial, a formação do Mercosul e a valorização da moeda brasileira.

Contudo observou-se que a produção nas demais Regiões brasileiras foi mais afetada por estas políticas, resultando em quedas significativas na área plantada e na produção de arroz. No sentido contrário a estas tendências, a produção gaúcha vem incrementando significativamente nestes últimos dez anos, possibilitando a este setor uma maior participação no mercado brasileiro. 
As razões para estas diferenças são diversas, desde as vantagens obtidas através de recursos naturais mais adequados à produção de arroz, quanto pela menor incidência destes fatores potencialmente negativos (políticas que afetam a agricultura) sobre o produtor de arroz neste Estado, como pelo maior incremento tecnológico.

Uma das diferenças em termos de políticas agrícolas está na questão da redução do crédito. No periodo de 1985 a 1996, o que se observou foi uma maior estabilidade do crédito concedido para custeio em relação à diminuição significativa no restante do país, com exceção nos anos de 1995 e 1996. Neste anos ocorreu uma diminuição mais acentuada no crédito, o que resultou inclusive em uma redução na produção de arroz e diminuiu a competitividade deste setor no mercado brasileiro.

De maneira semelhante a redução dos preços mínimos pagos pelo governo afetoü principalmente as Regiões onde a produção de grãos e a agroindústria são mais distantes, como a Região Centro-Oeste.

Conseqüentemente, uma redução na oferta nas Regiões produtoras de arroz de sequeiro veio a estimular principalmente a produção de arroz no RS e as importações de outros paises, reduzindo a competitividade do arroz de sequeiro.

Da mesma forma, a abertura comercial e a formação do Mercosul vieram por reduzir ainda mais a produção de arroz de sequeiro e a produção das demais Regiões brasileiras. Incapazes de competir com os menores preços dos produtos importados e com a sua melhor qualidade, estas Regiões começaram a substituir a produção de arroz de sequeiro, pela produção de soja, milho e outras culturas.

Ao contrário das demais Regiões, o produtor gaúcho, sem muitas alternativas a desenvolver nas suas várzeas mal drenadas e com custos de produção mais próximos aos obtidos pelos outros países, começou a desenvolver e implementar novas tecnologias na lavoura gaúcha. Estas novas tecnologias permitiram ao produtor de arroz gaúcho diminuir a diferença em termos de eficiência na produção e a aumentar a produção de arroz e a sua competitividade no mercado brasileiro.

Portanto este conjunto de fatores analisados permite um entendimento dos determinantes internos que contribuíram para incrementar a produção de arroz gaúcho e possibilitaram um aumento da participação no mercado brasileiro e na sua competitividade. 


\section{BIBLIOGRAFIA}

ALVIM, Augusto Mussi. Competitividade do arroz gaúcho frente ao mercado internacional. Porto Alegre: UFRGS, 1998. (Dissertação em Economia Rural - $n^{\circ} 199$ ).

AS DIVIDAS da agricultura. Safras \& Mercados. Porto Alegre, ano 12, n. 259, p.1-3, 1997.

AS TENDENCIAS do mercado para 1993. Safras \& Mercados. Porto Alegre, ano 7, v. 147, p.1-3, dez. 1992.

FGV (Fundação Getúlio Vargas). Conjuntura Econômica. Rio de Janeiro: vários números, 1970 a 1995.

CNA (Confederação Nacional da Agricultura). Brasil aumenta importações agropecuárias do Mercosul. Revista Gleba - Informativo técnico. Brasília, ano 42, n.143, p.6-7.

FNP Consultoria \& Comércio. Agrianual 96 - Anuário Estatistico da Produção Vegetal. São Paulo: Argos Comunicação, 1996.

KUME, Honorio. A Liberalização das importações de produtos agricolas: a experiência dos anos 90. In: Comércio Internacional e Comercialização Agricola. Viçosa: UFV, p.177-197, 1995.

PERSPECTIVAS para o mercado mundial em 1996. Agroanalysis. Rio de Janeiro, v.15, n.9, p.30-32, 1996.

SILVA, José Graziano. Uma década perversa: As politicas agrícolas e agrárias nos anos 80. Campinas: IE/Unicamp, 1992. 
Anexo 1

Tabela 1A - Custos de produção de arroz irrigado no Brasil, 1997

\begin{tabular}{l|r|r}
\hline \multicolumn{1}{c|}{ Itens } & US\$/ha & Participação (\%) \\
\hline Terra de cultivo & 131,4 & 12,0 \\
Preparo de solo, drenagem e aplainamento & 130,9 & 12,0 \\
Adubo de base e cobertura & 67,4 & 6,2 \\
Semente & 60,3 & 5,5 \\
Adubação de base e semeadura & 16,4 & 1,5 \\
Rolagem & 1,7 & 0,2 \\
Irrigação & 139,8 & 12,8 \\
Canais e condutos & 25,5 & 2,3 \\
Taipas e remontes & 38,6 & 3,5 \\
Aguador & 25,2 & 2,3 \\
Adubação de cobertura & 11,4 & 1,0 \\
Controle de invasoras, pragas e moléstias & 60,3 & 5,5 \\
Colheita & 55,2 & 5,1 \\
Transporte interno & 33,6 & 3,1 \\
Fretes & 32,1 & 2,9 \\
Secagem & 68,2 & 6,2 \\
Administração & 29,5 & 2,7 \\
Estradas & 2,9 & 0,3 \\
Cercas & 7,0 & 0,6 \\
Instalações agricolas & 37,7 & 3,5 \\
Taxas & 55,1 & 5,0 \\
Juros de financiamento - custeio agricola & 36,5 & 3,4 \\
Juros sobre o capital próprio do custeio agrícola & 25,8 & 2,4 \\
Total & $1.092,5$ & 100,0 \\
\hline Fonte: IRGA, &
\end{tabular}

Fonte: IRGA, 1997. 